\title{
PHOTOGRAMMETRY, HBIM, AND DAMAGE ANALYSIS OF COSMIC RAYS PAVILION FOR RAISING AWARENESS TO ITS CULTURAL HERITAGE
}

\author{
S. Rajabzadeh ${ }^{*}$, M. Esponda ${ }^{2}$, L. Cordero Espinosa ${ }^{3}$ \\ $1^{*}$ Carleton Immersive Media Studio (CIMS), Carleton University, Ottawa, ON, Canada sepidehrajabzadeh@cmail.carleton.ca \\ ${ }^{2}$ Azrieli School of Architecture \& Urbanism, Carleton University, Ottawa, ON, Canada - 1125 Colonel By Dr, Ottawa, ON K1S 5B6 \\ mariana_esponda@carleton.ca \\ ${ }^{3}$ National Autonomous University of Mexico (UNAM) lailacorderoespinosa@gmail.com
}

KEYWORDS: Felix Candela, Pabellón de Rayos Cósmicos, Hyperbolic Paraboloid, National Autonomous University of Mexico (UNAM), Photogrammetry, Digital Documentation, HBIM.

\begin{abstract}
:
This paper presents a comparative approach between a digital documentation workflow using contemporary tools versus a traditional documentation technique for Felix Candela's hyperbolic paraboloid (hypar) modern heritage building: Cosmic Rays Pavilion. This documentation was undertaken to better understand the building's structure, its evolution, and to assess the performance of this concrete structure for future seismic and damage analysis. Furthermore, the paper discusses the challenges related to producing a Heritage Building Information Model (HBIM) of this building using point cloud data in Autodesk's Revit BIM-authoring software. This project states the importance of a parallel study between the traditional and the contemporary documentation methods; which led to discoveries about the current state of the extrados in the hypar after several earthquakes. Upon analyzing the HBIM and comparing it to the historical drawings, a gap was discovered between the moisture barrier membrane and the concrete shell. Visualizing the building in 3D provides a deeper and more accurate understanding of the current state of this pavilion and is one of many advantages of using digital technologies. The insights provided by digital documentation techniques and analyzing the historical images of the pavilion showed that the curvature of the pavilion has been modified over time. The results imply two hypotheses. First, the curvature profile has been altered due to earthquakes. Second, the modification is due to improper maintenance of the pavilion, namely, multiple additions of the membrane layers. This could not have been detected by solely relying on traditional documentation techniques.
\end{abstract}

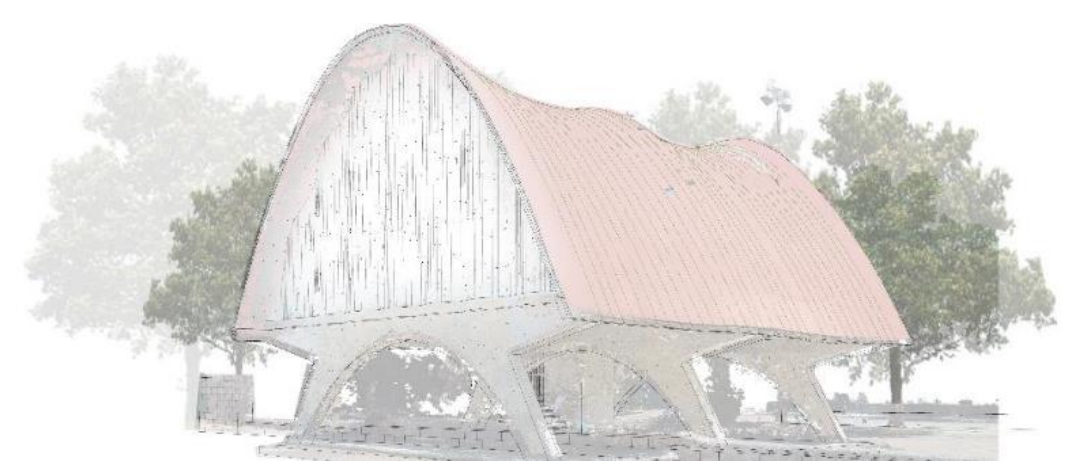

Figure 1. HBIM rendering of Cosmic Rays Pavilion based on the point cloud data (Drawn by Rajabzadeh, 2019).

\section{INTRODUCTION}

Felix Candela was born in Spain and emigrated to Mexico in 1939. He experimented with hypar geometry for most of his career. Cosmic Rays Pavilion, completed in 1951 in Mexico City was his seventh concrete shell built at that time, while it was the first hypar thin-shell concrete built in Latin-America (Mendoza, Esponda, Espinosa, Méndez, 2021). This pavilion is located on the UNESCO World Heritage campus of the National Autonomous University of Mexico (UNAM) with a 5/8" (16 $\mathrm{mm}$ ) thin reinforced concrete shell at the crown, increasing to 1 $1 / 2 "(37 \mathrm{~mm})$ at the base (Garlock and Billington, 2008). The structure still stands after 70 years; despite undergoing 3 major earthquakes in 1985, 1999, and 2017 with magnitudes over 7.1. The pavilion was the thinnest highly durable shell membrane (Analis, 2008). The strength of the pavilion is derived from its hypar geometry and craftsmanship (Faber, 1963). It was important for the structure to be as thin as possible since its original purpose as a physics laboratory required cosmic rays to pass through the roof and to a device inside for measuring neutrons (Analis, 2008). The pavilion now serves as a storage space for board games and sports equipment.

The preliminary objectives for the project were to produce two sets of drawings from the existing pavilion using two methods: traditional and digital. The two sets of drawings were then overlaid and compared with the original construction drawings of the pavilion done by Candela. The comparison between the digital model and the original construction drawings revealed the extent of decay a building can go through without proper maintenance, and the importance of consistent conservation efforts for this modern structure. 
The traditional documentation was done by Laila Cordero over a period of 64 days in the Fall of 2018. Cordero, a recent graduate from UNAM, applied a technique using ropes and measuring devices to document and produce a new set of 2D drawings of the current state of the building. The digital approach was done by Carleton University Students and Carleton's Immersive Media Studio (CIMS) from Canada over 49 days in May and June 2019. A team of four students spent six days in Mexico City recording the pavilion and one of them, Sepideh Rajabzadeh, continued working on the project with professor Mariana Esponda until completion in Canada. This team used digital equipment such as DSLR cameras, a drone, and computer software to capture the existing geometry on site. The other 43 days were spent at CIMS in Canada processing the photogrammetry and 3D point cloud data, producing HBIM and 2D drawings.

Due to the lack of research for the conservation of $20^{\text {th }}$ century concrete buildings, this report has two main aims: first, how to apply nondestructive techniques (traditional and contemporary) to document hypar structures, and second, understand the current state of modern structures, specifically concrete shells in Mexico, to secure their protection and accurate conservation. The goal is to generate an awareness and to encourage more professionals from diverse fields to address the issue of proper interventions for modern architecture.

\subsection{Design}

The proposal asked for an enclosed space for a minimum roof thickness of $15 \mathrm{~mm}$ over the span of 10x5 meter. This proposal was constructively unaffordable for the technological advances of that time. Architect Jorge González Reyna, designed a cylindrical vault to cover the roof span as a response to the design, but it did not meet the required thickness. The next step was to go to "Cubiertas Ala" in search of a structural advisor. By 1951, this company which was co-founded by Candela began to develop high-tech concrete shell structures at highly accessible prices and was acquiring a reputation for execution within the country. Candela joined the collaboration requested by Arch. Reyna for this project (Cordero, 2019), and changed the original design to a hypar because he stated "the extreme thinness would require the extra stiffening offered by this form" (Faber, 1963).
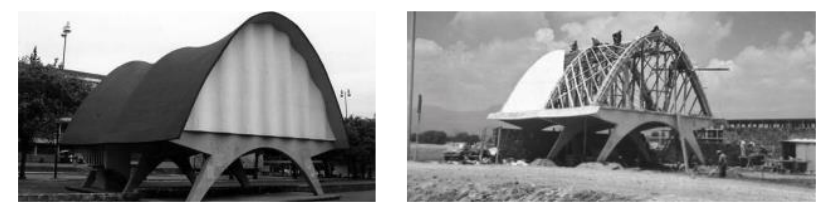

Figure 2. Left: Cosmic Rays Pavilion, Mexico City, 1951 (Architectuul [website], 2019) Right: Cosmic Rays Pavilion in Construction, Mexico City (Del Cueto, 2011)

"Candela was able to achieve a solution endowed with compelling three-dimensional force. On the ground level, three paraboloid-shaped arches rise up with protruding support. The upper portion of the arches serves as the structural framework of the laboratory, and the encompassing concrete membrane seems to rest in place above it without being anchored to the ground. The beauty of the design's three-dimensionality emerges directly from its clever devised proportion. As thin discs with wellbalanced pressure and stress points, the arches do not seem to dominate the design: in light of the lateral bearing areas, the former seem to function like supports on the one hand and, because of their parabolic shape, convey a sense of elasticity on the other" (Analis, 2008).

\subsection{Construction}

Colin Faber describes in his book Candela: the shell builder published in 1963, that Candela wrote a few pages explaining why the shape of a hypar would support itself based by a hypothetical analysis in order to obtain the contract with the UNAM authorities. It was easier done than said, because hypar geometry can be achieved by a formwork of straight boards that intersect at 60-degree angles.

After building Cosmic Rays, Candela went on to build and to explore more hypar structures. Later on in his career, he realized that he did not need to add the three stiffening arches to increase the strength of the pavilion, Candela recognized that the shape was strong enough without the arches (Faber, 1963).

\section{THE DOCUMENTATION WORKFLOW}

Two methods were used to document the pavilion:

- Cordero's traditional method: ropes and measuring tools by hand, and 2D drawings.

- CIMS' digital method: DSLR cameras and a drone to capture, photogrammetry, an HBIM produced from point cloud data, and 2D drawings.

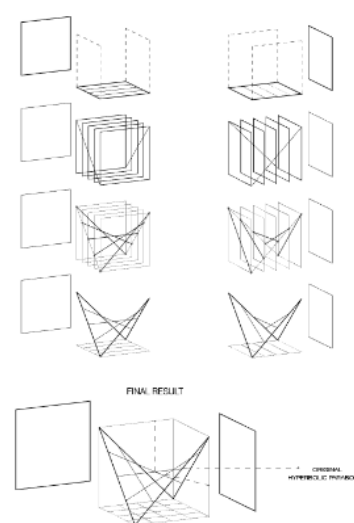

a)

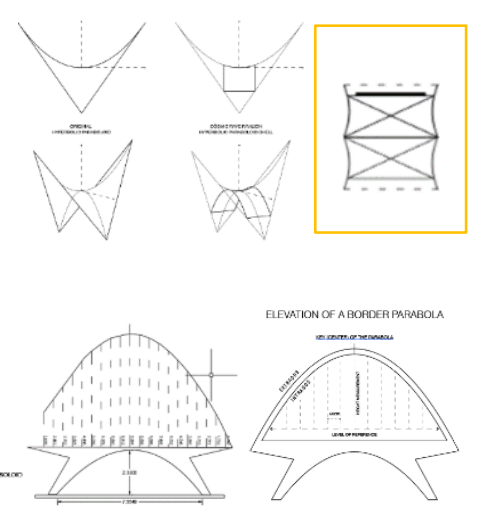

b)
Figure 3. a) Analysis of the shell's geometry (formation of hyperbolic paraboloid shape using straight lines). b) Illustrating ropes that Cordero used (the plan drawing in the yellow box) (Cordero, 2019)

\subsection{Laila Cordero's workflow}

Cordero, one of the authors, did a complete analysis of the building's geometry. Through her research she concluded that the project existed in 3 phases: Structural Memory, Architectural Plans, and Architectural Survey.

Structural Memory, through which, Candela unveiled - both with words and numbers - the design composition, the constructive solution, the quantification of the materials and the calculations that justified these decisions. It was a rough structural resistance check, where Candela determined the maximum forces on a cylindrical funicular vault. In this stage, Candela referred to the project as a preliminary design stage.

The Architectural Plans of the Cosmic Ray Pavilion, which are plans published in Faber's book. Currently, this book is the most complete bibliography of Candela's works. It contains adaptations and modifications of the drawings previously mentioned in the Structural Memory. The book also takes on a 
narrative approach about the construction process carried out on site. Furthermore, the book explains that the main difficulty was the experimental nature of the construction; one of such struggles were to keep the framework sturdy as they were pouring concrete over it by hand

Architectural Survey, is the documentation phase that was done by Cordero using traditional methods to capture the current state of the building. This stage showcased the discrepancies between the current geometry of the building versus what was first proposed in the Structural Memory and then in Architectural Plans while the built results still respect the characteristics of the initially proposed hypar geometry.
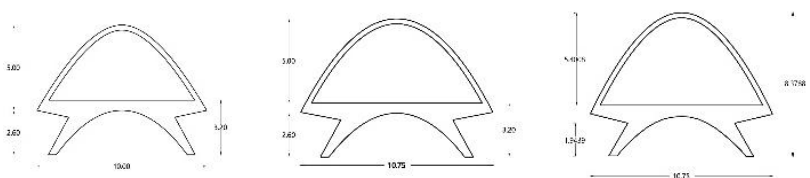

Figure 4. Cordero's comparison diagram of the 3 phases of the building: Left: Structural Memory, Center: Architectural Drawings, Right: Architectural Survey

Cordero started the measurements by locating two essential elements: an axis and a reference level to identify the guide plane perpendicular to the parabola. Ropes were then installed across the interior, connecting two legs of the parabolic columns at the bottom where they reached the floor. The rope was divided into $50 \mathrm{~cm}$ segments, and the height was measured by firing the distance meter twice which was positioned on a tripod. In the end, an average of the two measurements obtained at each point was calculated (Cordero, 2019).

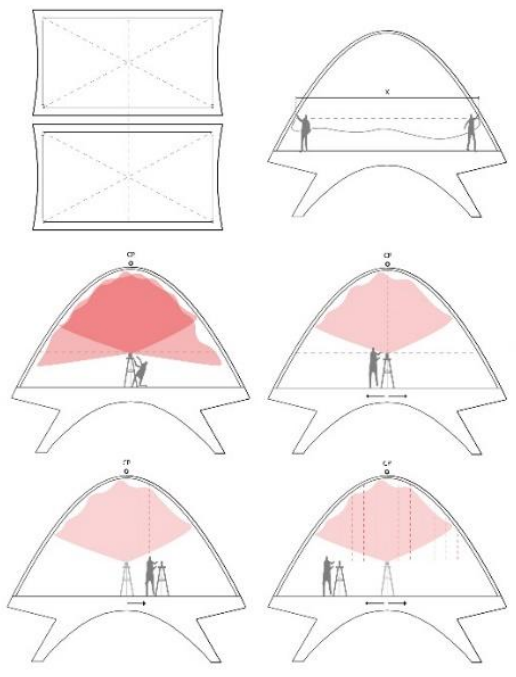

Figure 5. Cordero's diagram, showcasing her documentation process

Cordero's graduating thesis suggests the hypothesis that Candela's constructional drawings mentioned in Architectural Plans for Cosmic Rays Pavilion do not match the documented work Cordero produced in her survey. The plans and elevations that were published in the books and magazines were of a preliminary nature and they were drastically modified during construction. This discrepancy between the constructional drawings and the as-built structure exists because hypar structures had not been constructed before in Mexico, and there was a learning curve for the construction process which did not allow for a perfect recreation of the design. Also, throughout studies of the archival information, it was noted that this building had been modified multiple times during the construction because of its experimental nature. These are just a few of the reasons why this building needs to be preserved and properly maintained (Cordero, 2019).

\subsection{CIMS' workflow while in Mexico (NPNT internship)}

Part of the research for this project was supported by New Paradigm New Tools for Architectural Heritage in Canada (NPNT) research program supported by the Social Sciences and Humanities Research Council of Canada (SSHRC). The internship program focuses on using emerging digital technologies including the digitization of existing buildings using tools such as Photogrammetry with DSLR cameras and computer software. Some of the benefits of this documentation method explored through the NPNT program are efficiency of labour and ease of gathering data, while providing great accuracy.

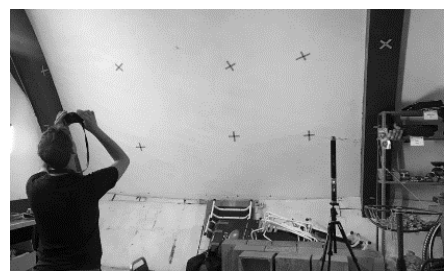

Figure 6. One of the Canadian students collecting interior photogrammetry data of the pavilion using a handheld DSLR camera.

The project started with a tour of UNAM, Mexico City, a site visit of another hypar in Mexico - Los Manatees — highly damage after earthquake in 2017, as well as a lecture on Felix Candela and his legacy by Dr. Juan Ignacio del Cueto RuizFunes. Then, the documentation of the Cosmic Rays Pavilion began. Techniques used during this time included the use of an Unmanned Aerial Vehicle (UAV) to capture aerial photography of the roof and its curvature, as well as the site. Also, handheld cameras including the Nikon D5200, 24.1 MP (APS-C), and Nikon $40 \mathrm{~mm}$ Macro Lens were used for terrestrial photogrammetry. Furthermore, an interior and exterior material catalogue using a gray chart was recorded.

Throughout the week, more interior and exterior photogrammetric images were taken as well as context elevation photos followed by an exterior condition assessment. The quality of photogrammetric models and data were tested while on site as well as the quality of elevation photos using Bentley ContextCapture and Adobe Photoshop. This was important to ensure all documentation was collected prior to leaving the site.

The exterior condition assessment of the pavilion, in May 2019, disclosed conditions that are mainly caused by human interactions as well as moisture penetration. A few examples include moisture and staining of plaster, plaster spalling, flaking plaster, profile detachment, concrete spalling, exposed rebar and reinforcement corrosion crack in concrete found in one of the
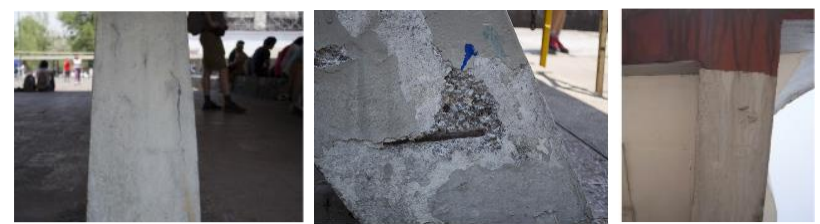

Figure 7. Exterior condition assessment. Left: exposed rebar reinforcement corrosion crack. Center: Concrete Spalling:

Right: Moisture and Staining of Plaster (Pictures taken by Canadian students) 
exterior supporting columns on the ground level, which if not treated as soon as possible may result in structural damage.

\subsubsection{CIMS' photogrammetry workflow}

The team placed target points on the inside and the outside of the building. Since the interior walls were painted plain white without any noticeable texture, the team used more than usual number of targets to increase accuracy.

The following methods were used to for Interior data collection:

- Method 1: To capture details

- Method 2: To capture sense of space

Exterior data collection:

- Method 1: To capture all terrestrial data

- Method 2: To capture all the site and the roof data with a drone

\subsubsection{Interior data collection - Method 1: To capture details}

Each interior elevation was divided into four vertical and three horizontal sections. As shown in figure 8 , the team started with the first vertical section from the top left, while making sure the camera stayed directly in front of each vertical section. Two portable lights were placed on either side of the camera pointing towards the subject at 45 -degree angle. This method of lighting eliminated unnecessary shadows.

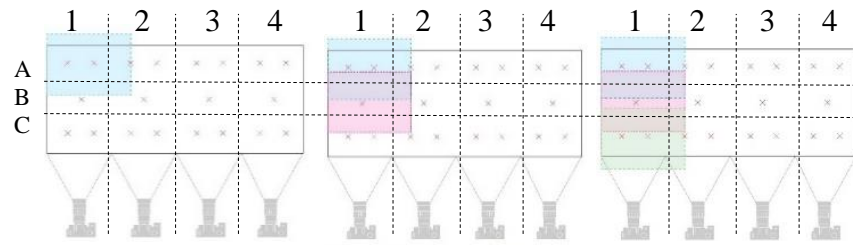

Figure 8. East Elevation (interior wall). Red " $\mathrm{x}$ " are target points. Left: blue square shows the first shot (notice how it overlaps $1 / 3^{\text {rd }}$ of the grid below and the grid on the right of the shot). Center: Pink square is the Second shot. Right: Green square is the third shot. (Drawn by Rajabzadeh, 2021)

The upper left square, A1, was captured first, then the rest of the wall was captured in a top-down manner while making sure each shot overlapped $1 / 3^{\text {rd }}$ of the previous shot. The team made sure at least three same target points were captured in three photos. This method was repeated to capture all four interior elevations.

\subsubsection{Interior data collection - Method 2: To capture sense of space}

Unlike method 1, images in this method are not for capturing details, but for capturing the perspective and sense of pace for the software. The camera was farther away from the wall and only changed locations three times: left, center, right. It was first placed on the left side of the room pointing at the left side of the wall. The rest of the wall was captured in a left-right manner while making sure each shot overlapped $1 / 3^{\text {rd }}$ of the previous shot. Then, the camera was placed in the center of the room pointing at the center of the wall to capture the elevation from this angle. Lastly, the camera was placed on the right side of the room, and it collected data from that angle (Figure 9).

\subsubsection{Exterior data collection - Method 1: To capture all terrestrial data}

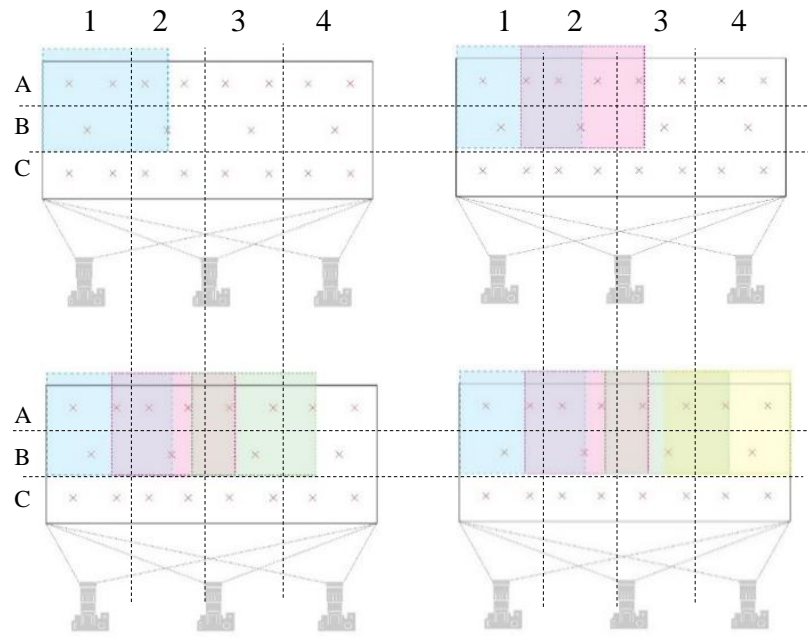

Figure 9. East Elevation, perspective data collection. Red " $\mathrm{x}$ " are target points. Top Left: blue square shows the first shot (notice how it captures a wider range and overlaps $1 / 3^{\text {rd }}$ of the grid to the right of the shot). Top Right: Pink Square is the second shot. Bottom Left: Green square is the third shot

Bottom Right: 4th shot. (Drawn by Rajabzadeh, 2021)

Three students used three DSLR cameras to capture as much data as possible from the exterior of the building.

Much like the interior data collection, after placing target points on the exterior and on the ground while collection measurements, each exterior elevation was divided into vertical and horizontal sections. Also, the team made sure the camera was directly in front of each section as much as possible. Capturing the exterior photogrammetry data was done by going around the building and taking photos after every step while overlapping $1 / 3^{\text {rd }}$ of each shot with the previous one (Figure 10).

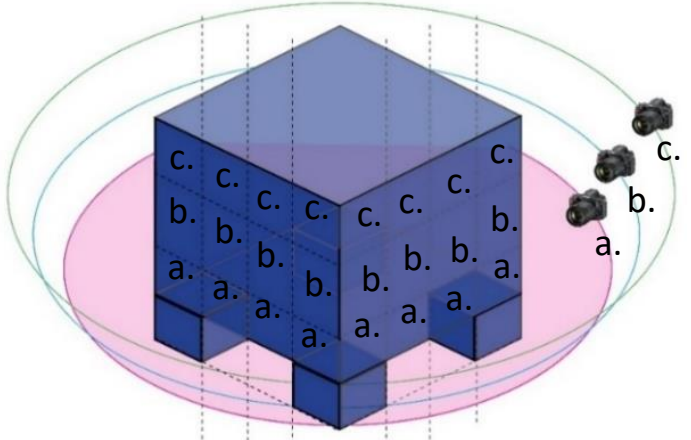

Figure 10. Diagram showing how the exterior photogrammetry was done. a) Below eye-level and closest to the building. b) Eye-level. c) Above eyelevel and farthest away from the building. (Drawn by Rajabzadeh, 2021)

In this method, three rounds of data collection were done. (Figure 10):

a) Below Eye-level (closest to the building): Using the camera on tripod to provide the same height for all the images. This round captured details on the building as well as the underneath of the building since it is lifted above ground.

b) Eye-level: The camera was held by hand for this height. The distance to the building was farther away from option a. 
c) Above Eye-Level (farthest away from the building): Using tripod, following the same process while being farthest away from the building. At this height, the team was not recording data for small details, but rather, to capture the site and the curvature of the roof.

\subsection{CIMS' workflow after documentation (NPNT internship)}

While students were getting to know the "contemporary tools" such as the photogrammetry software Agisoft Photoscan, it was decided to create the interior and exterior point cloud models separately and merge them together to create one unified point cloud model. (Figure 11)
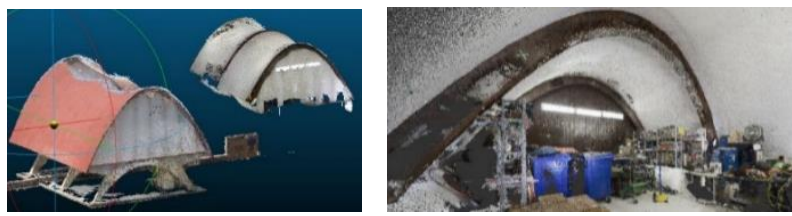

Figure 11. Left: Two separate interior and exterior Point cloud data of the pavilion in CloudCompare software. Right: Shows interior point cloud data in Agisoft Photosca Software. (Produced by Rajabzadeh, 2019)

\subsubsection{Workflow in Agisoft Photoscan Software}

The diagram in figure 12 shows the complete digital workflow that was performed to produce a point cloud model from photogrammetric data.

As mentioned, the team placed target points on the interior walls of the pavilion during data acquisition. As shown in figure 13, after importing all the images into the Agisoft Photoscan software, target points were used to align the images together in the software. The previously measured distance between the targets was used to accurately scale the model in Agisoft Photoscan (CIMS, 2018).

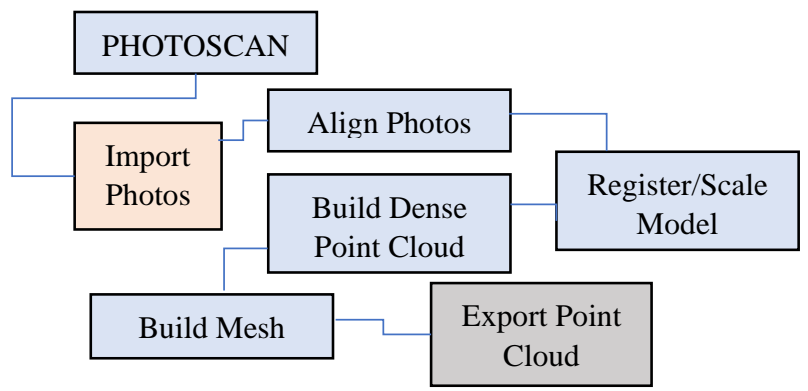

Figure 12. Photogrammetry workflow in Agisoft Photoscan (CIMS, 2018)
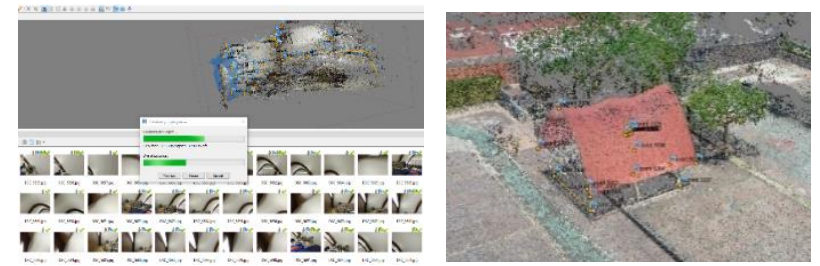

Figure 13. Left: Photo aligning process in Aigsoft Photoscan Software using the target points. Right: Dense cloud of the whole site created in Agisoft Photoscan Software (Produced by Rajabzadeh, 2019)

Furthermore, a dense cloud was built to create the 3D point cloud model. Then, it was exported out of this software and imported into Revit to create an HBIM of the pavilion.
Once the point cloud data was imported to Revit, different strategies and protocols were applied to find the best methodology in order to create the double curved roof accurately. These different methods and their challenges are briefly mentioned in the challenge section of this paper. The method that proved to be most accurate is explained in the following section:

\subsubsection{Workflow in Revit Software}

Both interior and exterior point cloud data were imported into Revit. First, it was important to identify different elements of the building in order to understand how to model the pavilion efficiently. The roof membrane was considered an exterior element which was captured best via the exterior point cloud data; while the concrete shell itself was considered an interior element, which was captured best via the interior point cloud data. This increased the ease by which the membrane and the concrete shell could be modelled, since the different point clouds can be turned on and off in Revit using visibility and view settings. The strategy to capture the shape of the hypar is shown in Figure 14.
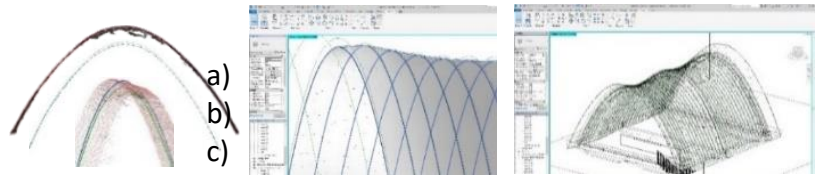

Figure 14. Left: a) Thin section of the point cloud model of the roof membrane (CIMS, 2018), b) Model lines outlining the roof membrane and the concrete shell (BIM, 2017)(Learn, 2016), c)

Thin section of the roof membrane with model lines (CIMS,

2018). Center: Roof membrane and the concrete shell model lines. Right: Green: The roof membrane model lines. Blue: The concrete shell model lines. (Drawn by Rajabzadeh, 2019)

Through the roof, thin sections were taken by introducing vertical reference planes in close proximity to one another. Using the section box tool, the curvature of each section on the roof was carefully traced with model lines. Then, while selecting all the model lines, the "Create Form" tool was used to create a surface that followed the curvature, deformations, and deviations of the documented roof membrane.
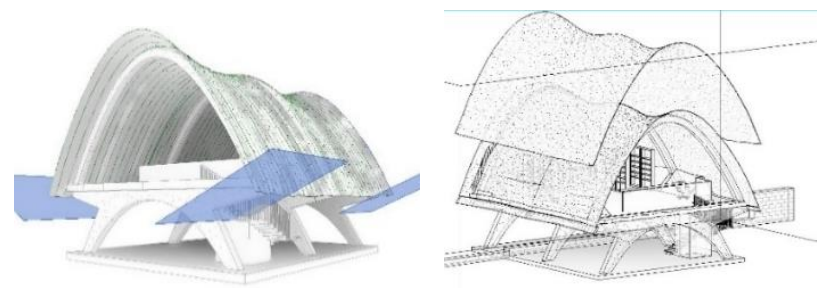

Figure 15. The surfaces of the roof membrane and the concrete shell are given thickness. Modeling them separately allows for exploded axo. diagrams and further studies of each component separately. (Drawn by Rajabzadeh, 2019)

This Process was repeated to model the concrete shell, using interior point cloud data. Lastly, both surfaces were given proper thicknesses based on their point cloud data (Figure 15). The HBIM includes structural and mass elements together, and is developed accurately based on the existing conditions and geometry of the pavilion because of the original objectives of the project. However, this model could further be studied for seismic load analysis by converting it into a model for structural analysis. 


\section{CHALlENGES}

Since the objectives of this project were to introduce a new method of documentation, compare digital method with traditional method, and provide the local staff with the capacity to perform the digital documentation, there were many lessons learned for the students involved which are mentioned below.

\subsection{Receiving drone data from Mexico}

Although the drone was used while the team was still in Mexico, the drone data was only received in Canada when only two weeks of the project was remaining. It was delayed due to security reasons prior to leaving Mexico. The Canadian team recorded the exterior data from ground level by handheld cameras and the point cloud model was missing data from the top of the roof. Once the drone info was received, the exterior photogrammetry was reprocessed to include the data from the top of the roof, aligned with the interior point cloud data, and then imported into Revit to be modelled (Figure 16).
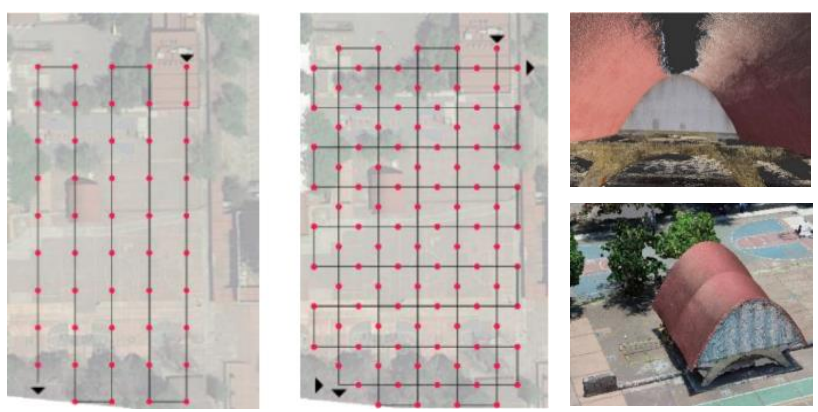

Figure 16. Left: First round of drone movement, red dots are the shots taken. Center: Second Round. Top-Right: Exterior point cloud model before receiving drone information, the top part is missing. Bottom-Right: Exterior point cloud model after receiving drone data. (Produced by Rajabzadeh, 2019)

\subsection{Merging interior and exterior point cloud data manually}

One of the main lessons learned in this project arose from the fact that the main strategy was to rely on point-to-point correspondences for the software to merge the interior and the exterior point clouds. Later on, it was understood that there was a lack of redundancy in the process. Although there were thorough hand measurements taken by the team, no ground control points were collected in case of the software failure to stitch the pictures together.

Since the pavilion has no windows to the outside, the only common area between the interior and exterior is the railing on the stairs. Although there are many images of this part, the software could not reconcile the two point cloud data fully buy itself. It was surmised that this did not work because the exposure levels in the images of the railings from inside of the pavilion were very different from those of outside. Therefore, the software could not recognize matching features between the sets of photographs and failed to merge them (Figure 17).

Consequently, the two point clouds had to be merged manually, by matching all the measurements as closely as possible in order to reduce the errors.

Having encountered such challenges played an essential role in helping the team understand the limits of the software. Moving
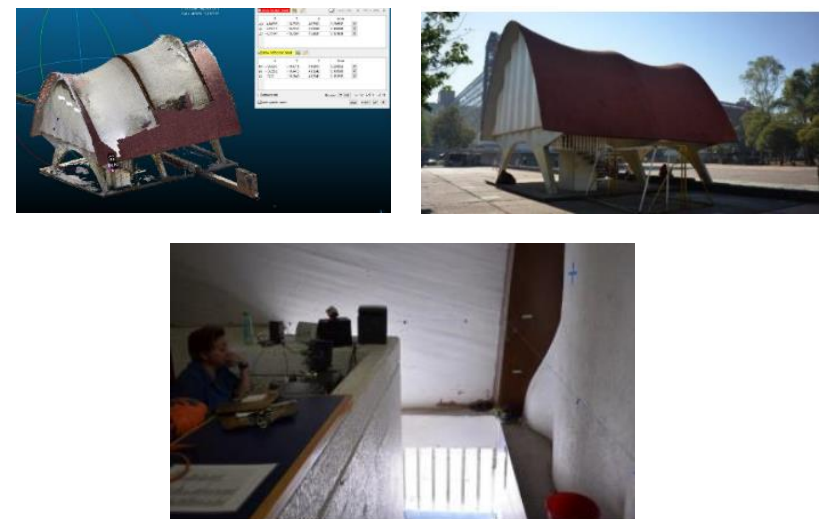

Figure 17. Left: Software not being able to merge the two point clouds properly - CloudCompare (Aligning, 2016). Right:

Standing on the outside looking toward the railings which is the entrance to the pavilion. Bottom: Standing on the inside

looking at the railings. (Pictures taken by Canadian students, 2019)

forward, it is recommended to have at least three common targets that are captured by both the interior and exterior photographs.

The team strongly believes that speaking about challenges along the way would help future students and stakeholders, who wish to use this technology for their first time, not be afraid of all the steps that go into using photogrammetry. This technology is accurate enough for such a small scale of a project, that the lack of ground control points did not change the outcome of the project. However, it is worth mentioning that for larger projects, collecting ground control points is necessary.

\subsection{Location of the Building}

Beyond the technical challenges, the location and circumstances around the building were an added strain to the data collection process; Cosmic Rays Pavilion is located on the busiest part of the campus of UNAM. The campus could not restrict access for the documentation work, so there were frequently many students near the pavilion. The team had to take many images at different times of the day and different days of the week, with different weather and lighting conditions, in order to record high quality images for the production of high quality point cloud data without people and other obstructions in any of the photos. The process of colour correction was performed to create true colours of the images and to reduce their different lighting condition.

\section{NEW DISCOVERIES}

Once the HBIM was developed, more in-depth studies were done to understand how the building was constructed and evolved throughout time. One of the more interesting discoveries was that there is a gap between the red roof membrane and the hypar concrete shell. Further studies on the model revealed that this gap varies throughout the entirety of the pavilion, and it is at its greatest in the middle of the roof (Figure 18).

Once this new piece of information was shared with Cordero, she provided the team with thermal images which strengthened such findings about the poor maintenance and vulnerable state of the concrete roof (Figure 18). 

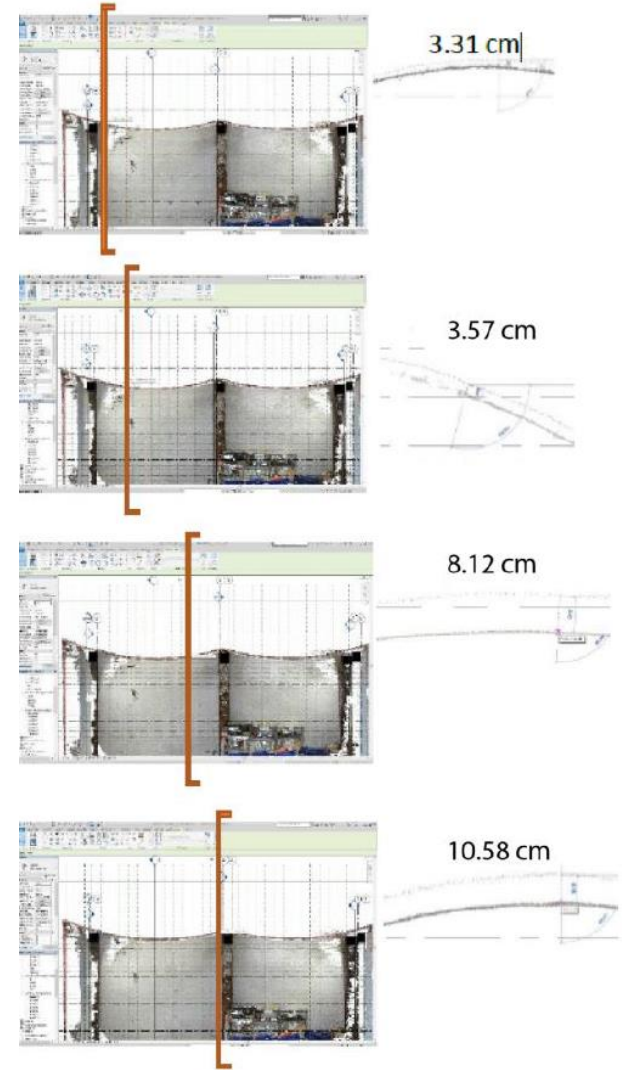

Figure 18. Series of sections showing the gap size between the roof membrane and the concrete shell - East Section (Drawn by Rajabzadeh, 2019)

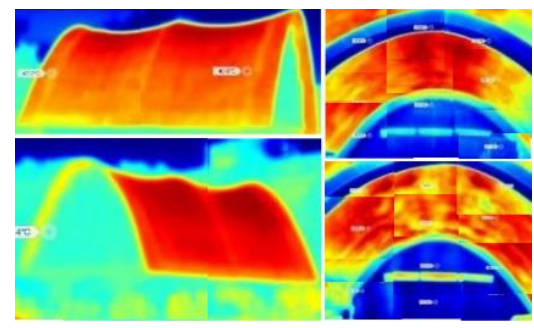

Figure 19. Thermal images (Cordero, 2019)

In Figure 19, the picture on the left shows an even distribution of heat on the roof membrane taken from outside, but the picture on the right shows uneven heat distribution on the concrete shell itself taken from the inside. The extent of the membrane failure was apparent in the concrete shell through the thermal images. The image reinforces the discovery of the gap between the roof membrane and the concrete shell, and the non-uniformity of the gap. This new piece of information shows the roof membrane has not been maintained properly over the years. It was speculated that the poor maintenance of the membrane may have led to its cracks and openings, which allowed water and moisture into the concrete shell resulting in its gradual deterioration.

\section{DELIVERABLES}

At the start of the project, the team sought out to compare the different recording approaches, traditional and digital, but eventually realized that there were differences between the current state of the building and the original drawings.
When the two elevation drawings from each documentation method were overlaid, they aligned very well with negligible differences. However, once the new drawings were overlaid with the original construction drawings, they did not correlate (Figure 20).

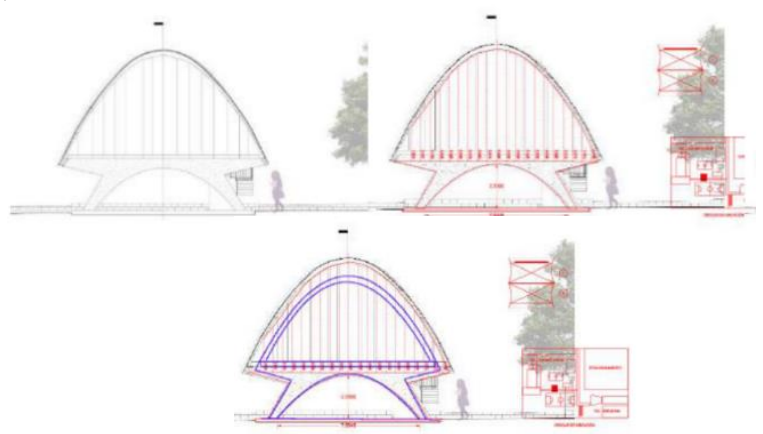

Figure 20. Top Left: 2D drawing done by Rajabzadeh using Revit software and point cloud data. Top Right: In red: Cordero's drawing is overlaid. Bottom In blue: Original construction drawing by Candela) are overlaid

Since Cosmic Rays Pavilion was Candela's first hypar, he learned how to solve constructional challenges with this geometry along the way during construction. The lack of accurate construction, or as-built drawings of this pavilion emphasizes the importance of protecting this building. The original construction drawings were only done as a guideline for how to approach the construction process of the hypar using reinforced concrete, however the execution and final product showed a different result.

\section{CONCLUSION}

After the HBIM creation of the pavilion, collaboration with Cordero's traditional measurements, and a thorough study of the archival documents; the results show that the traditional and contemporary techniques produced the same results. However, using new digital techniques led to more in-depth discoveries of the state of the building. Also, the hypothesis, which speculated that there is a gap between the concrete shell and the roof membrane, which was a result of poor maintenance, was proven to be true. One of the stakeholders, Julio Valencia Navarro (Dirección General de Obras y Conservación) from UNAM, has since confirmed that there is a gap between the roof membrane and the concrete shell. Over the years, there has been moisture damage on the concrete shell due to the improper removal of the waterproofing roof membrane which this long-term damage is altering the curvature, and probably the capacity of the pavilion. Currently, the findings of this pavilion show no record of structural damages that can be associated with the change of function or with the devastating earthquakes of 1985, 1999, and 2017. The main damages to the shell have been caused by inadequate waterproofing treatments over the years (Mendoza, Esponda, Espinosa, Méndez, 2021). Nevertheless, if the building continues to not be maintained properly, the moisture damage might allow future earthquakes to have a greater impact on this modern heritage building.

Although the project was missing control points, the relatively small scale of the project allowed for the interior and exterior point cloud data sets to be compiled manually. The target points were accurate to allow for a comprehensive point cloud data sets of the pavilion to be created using photogrammetry. While laser 
scanners can quickly produce a point cloud, they are less accessible and more expensive than DSLR cameras and drones. Using photogrammetry technique helped facilitate a maintenance approach to visually show which part of the building required immediate attention.

The collaborative and comparative approach developed for recording the as-found conditions of the Cosmic Rays Pavilion brought forth an opportunity for the local staff to have a worthwhile learning experience about the value of this building and proper conservation techniques. Moreover, the HBIM can be studied further for seismic analysis on the concrete shell, damage scenarios, and risk management purposes in the future.

Finally, it was crucial to continually reference the archival images and to understand the traditional technique that was used in order to better understand the building, and to make sure the analyses provided by the contemporary tools were accurate.

Professor Esponda anticipated another visit to the site in Mexico in 2020 to capture more detailed data, but due to the pandemic, further studies of this project on site must be postponed at this time.

\section{ACKNOWLEDGEMENT}

This research was supported by the Social Sciences and Humanities Research Council of Canada (SSHRC). Special thanks go to Professor Stephen Fai (principal Investigator of the New Paradigm/New Tools internship program and Director at CIMS), Lara Chow (Associate Director at CIMS), Professor Mariana Esponda for leading the project, Carleton Immersive Media Studio (CIMS), Carleton University. Thanks to Adrian Soble, Khadija Waheed and Luis Panchi for helping gather the data for the project. Laila Cordero Espinosa for sharing her undergraduate thesis. Special thanks to Dr. Xavier Cortes Rocha, Dr. Juan Ignacio del Cueto Ruiz-Funes, Mtro. Julio Valencia Navarro (Dirección General de Obras y Conservación), Arq. Alberto Hernández, EPY CIG Company: Ing. Alejandro Rodriguez Garcia, Ing. Miguel Eduardo Chavez Huerta, and Alejandro Minero Huerta for exchanging their knowledge. National Autonomous University of Mexico (UNAM) for allowing the team to work on the site for data collection.

\section{REFERENCES}

Ace D., Marrs J., Santana Quintero M., Barazzetti L., Demas M., Friedman L., Roby T., Chamberlain M., Duong M., Awad R. (2019). Documenting Nea Paphos for Conservation and Management. Carleton Immersive Media Studio (CIMS) Carleton University Canada, Politecnico di Milano, Department of Architecture, Built Environment and Construction Engineering Italy, Getty Conservation Institute U.S., Department of Antiquities of Cyprus. [online]. DOI:

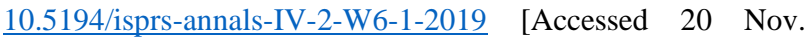
2019].

Aimond, F. F. (1936). Etude statique des voiles minces en paraboloide hiperbolique, travaillant sans flexion. memories de la ASCC. INT. DESPONTS ET CHARPENTES. VOL. IV.

Aligning \& Merging .DP Data in CloudCompare. DotProduct Youtube. (2016). Available at: https://www.youtube.com/watch?v=48x|LOe9d7|\&fbclid=|wA
R0PieUuwsVVbM1--1764xM2HvTufFdLQuAvqML0BEfMjEu nj-zfbzgM

BIM - Revit 3D Organic Form 03 Tensile Structure. Non-Stop Learning101 Youtube. (2017). Available at: https://www.youtube.com/watch?v=9_jJBtKGLyc\&fbclid=IwA R1PrpN6Gw7iNQWyo5K1QyPlef 1NJasWfYVf7 aX5ed8uDc op-rY9AcSVE

Carleton Immersive Media Studio (CIMS). (2018). Processing in Photoscan, pre-training workshop. Carleton University, Ottawa, Canada.

Cosmic Ray Pavilion. Architectuul.com. Available at: http://architectuul.com/architecture/cosmic-ray-pavilion

De Anda Alanis, E. X. (2008). Candela. Taschen, Mexico.

Del Cueto Ruiz-Funes, J.I. CANDELA ACE. Acción Cultural Española (AC/E), TF Graphic Arts, (2011). Available at: https://www.accioncultural.es/media/Default\%20Files/files/pub $\underline{\text { licaciones/files/catalogo_candela.pdf }}$

Dr. Juan Ignacio del Cueto Ruiz-Funes (2019). Interview.

Faber, C. (1963). Candela: The Shell Builder. New York: Reinhold Pub. Corp

Flelix Candela, Major Works. The Princeton University Art Museum, (2008). Available at: https://artmuseum.princeton.edu/legacyprojects/Candela/cosmicrays.html

Godin A.A. (2018). Algonquin BIM workshop tutorials. Carleton Immersive Media Studio (CIMS) Carleton University, Ottawa, Canada.

Cordero Espinosa, L. G. Undergraduate tesis. (2019). Pavellón de Rayos Cósmicos: pasado, presente y futuro. National Autonomous University of Mexico, Mexico.

Learn revit in 5 Minutes- Mass forme Felix Candela. Niko G. Youtube. (2016). Available at: https://www.youtube.com/watch?v=mxwGfNWwMI\&fbclid=IwAR1Bjmc4i23eThRigbOeo7rCvh1jpNtyn2_tn_rbRe7XpEFTWDTEGq1tUk

Mendoza Morfín, G. Campus Central C.U. (2019). Lecturas de un Patrimonio Vivo. Facultad de Arquitectura UNAM.

Moreyra Garlock, M.E., Billington, D.P. (2008, p. 91). Félix Candela: Engineer, Builder, Structural Artist. New Haven, Conn: Yale University Press.

Morganti, C., Bartolomei, C. (2018). Digital Survey and Documentation of La Habana Vieja in Cuba. In: Ioannides M., Martins J., Žarnić R., Lim V. (eds) Advances in Digital Cultural Heritage. Lecture Notes in Computer Science, vol 10754. Springer, Cham. DOI: 10.5194/isprs-archives-XLII-2-W8-1632017 [Accessed 20 Nov. 2019].

Mendoza, M., Esponda, M., Espinosa, L.C., Méndez, V. (2021). The Cosmic Rays Pavilion: the first hypar concrete shell in Latin-America, constructed at Ciudad Universitaria campus, Mexico City (UNESCO World Heritage Site). [Accessed 26 June. 2021] 